\title{
INTRODUCING BURNUP CREDIT FOR EXPANSION STAGE 2 OF THE EXTERNAL SPENT FUEL POOL AT GÖSGEN NPP
}

\author{
Axel Hoefer ${ }^{1 *}$, Martin Basler ${ }^{2}$, Oliver Buss ${ }^{3}$, Gaëtan Girardin ${ }^{2}$, Fabian Jatuff ${ }^{2}$, \\ Lukas Meyer ${ }^{2}$, Leo Ornot ${ }^{2}$, Detlev Rossbach ${ }^{3}$, Wolf Stoll ${ }^{3}$ \\ ${ }^{1}$ Framatome GmbH Karlstein \\ Seligenstädter Strasse 100, 63791 Karlstein, Germany \\ ${ }^{2}$ Kernkraftwerk Gösgen-Däniken AG \\ Kraftwerkstrasse, 4658 Däniken, Switzerland \\ ${ }^{3}$ Framatome GmbH Erlangen \\ Paul-Gossen-Strasse 100, 91052 Erlangen, Germany \\ *axel.hoefer@framatome.com
}

\begin{abstract}
We present a summary of the actinide-plus-fission-product burnup credit criticality safety licensing analysis for Expansion Stage 2 (ES2) of the external spent fuel pool at Gösgen nuclear power plant. In ES2, the nine Expansion Stage 1 storage racks currently installed in the external spent fuel pool are going to be supplemented by nine ES2 storage racks with a significantly reduced fuel assembly pitch. They are designed for loadings with fuel assemblies above a well-defined minimum required burnup. The objective of the criticality safety analysis is to calculate the minimum required burnup values for the uranium and MOX fuel assemblies to be stored in the ES2 storage racks. We use a methodology that allows us to take into account the reactivity effects due to variabilities and uncertainties of all relevant parameters involved in a burnup credit criticality safety assessment in a bounding manner. These include manufacturing tolerances of the fuel assemblies and storage racks, the irradiation histories and burnup profiles of the spent fuel assemblies, the bias of the depletion code used to calculate the isotopic inventories of the irradiated fuel, and the bias of the criticality code used to calculate the neutron multiplication factor of the considered storage configuration. A combination of different statistical procedures is used to evaluate and propagate the uncertainty information on the input parameters and translate it into statistical confidence statements about the neutron multiplication factor. It should be noted that the presented analysis is related to the first implementation of a significant burnup credit for wet storage of PWR fuel in Switzerland.
\end{abstract}

KEYWORDS: Burnup Credit, Spent Fuel Pool, Gösgen NPP, Licensing 


\section{INTRODUCTION}

In Expansion Stage 2 (ES2), the storage capacity of the external spent fuel pool (ESFP) at Gösgen nuclear power plant (KKG) is going to be increased from originally planned 1008 to 1206 fuel storage positions. For this purpose, the nine $8 \times 7$ Expansion Stage 1 (ES1) storage racks currently installed in the ESFP are going to be supplemented by six $9 \times 9$ and three $8 \times 9$ ES2 storage racks. The ES2 storage rack arrangement is shown in Fig. 1.

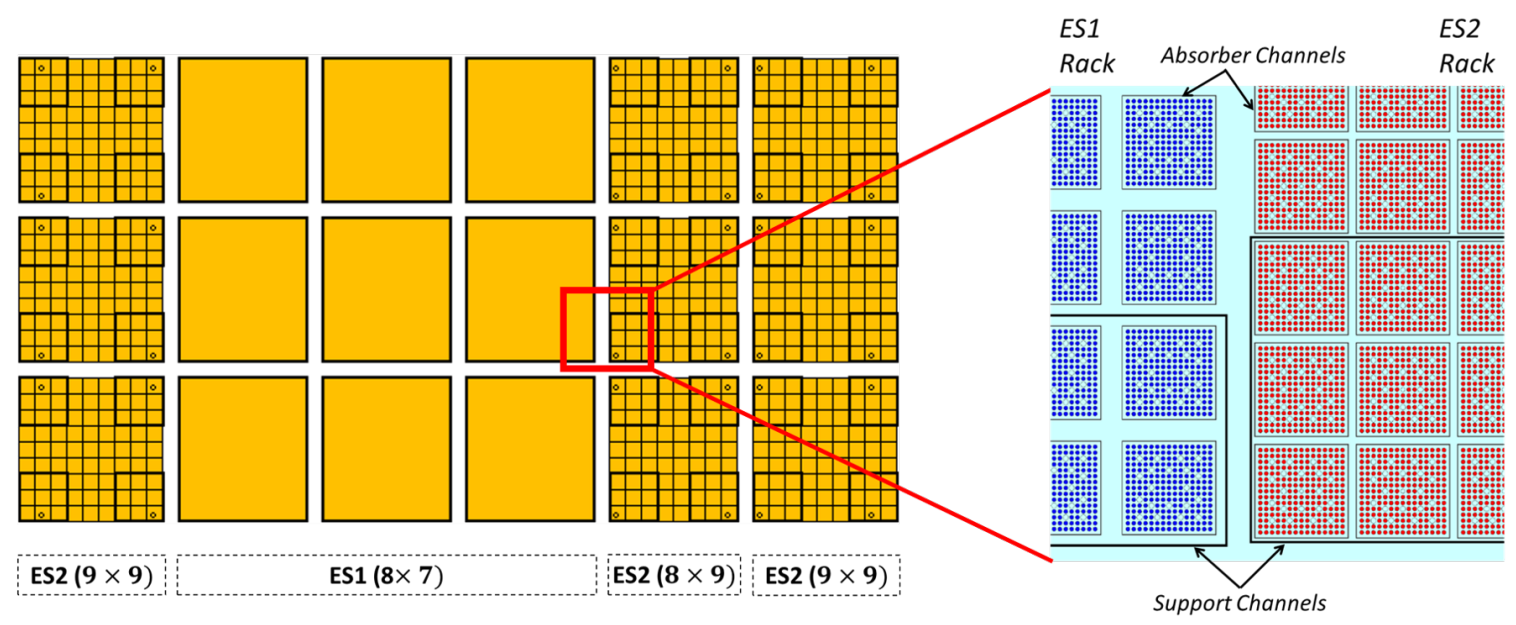

Figure 1: ES2 Storage Rack Arrangement in the Gösgen ESFP

Both the ES1 and the ES2 racks are characterized by flux trap designs where each storage position is equipped with a borated stainless steel channel. The major difference between the ES1 and the ES2 racks, however, is the significantly reduced fuel assembly pitch of $250 \mathrm{~mm}$ in the ES2 racks compared to $283 \mathrm{~mm}$ in the ES1 racks (see Fig. 1). Loadings of the ES2 racks are, therefore, associated with significantly higher neutron multiplication factors $k_{\text {eff }}$ than loadings of the ES1 racks. As a result, the criticality safety assessment for ES2 cannot be based anymore on the conservative fresh fuel assumption used in the ES1 licensing analysis of the Gösgen ESFP. For the criticality safety assessment of ES2, therefore, burnup credit is used to exploit the fact that the fuel assemblies to be stored in the Gösgen ESFP typically have burnup values of more than $45 \mathrm{GWd} / \mathrm{tHM}$ and thus have far lower reactivities than fresh fuel assemblies.

In the following, we present a summary of the (actinide-plus-fission-product) burnup credit criticality safety licensing analysis of ES2, in accordance with the Swiss ENSI-G20 guideline [1] and the German safety standard DIN 25471 [2], for loadings of the ESFP with uranium fuel assemblies from KKG with a maximum initial ${ }^{235} \mathrm{U}$-enrichment of $5.15 \mathrm{w} / \mathrm{o}$ and mixed oxide (MOX) fuel assemblies used in reactor cycles 19-33 at KKG. This analysis takes into account that the storage racks are divided into two regions. Region 1 is defined by the ES1 racks which are designed for fresh fuel and may, therefore, be loaded with fuel assemblies of any burnup. The ES2 racks defining Region 2, on the other hand, are restricted for loadings with fuel assemblies with a well-defined minimum required burnup. The minimum required burnup values of the uranium and MOX fuel assemblies to be loaded into the ES 2 racks are the results of the criticality safety analysis. 


\section{CALCULATION MODEL}

The criticality calculations are performed with the CSAS25 sequence of SCALE 6.1 [3], triggering the self-shielding modules BONAMI and NITAWL, and the KENO V.a Monte Carlo code for criticality eigenvalue calculations. To calculate the fuel composition of the spent fuel assemblies, burnup calculations are carried out with the TRITON depletion sequence of SCALE 6.0 [3], triggering BONAMI/CENTRM/PMC for cross section treatment, NEWT for transport calculations, and COUPLE/ORIGEN-S for depletion calculations. Both the criticality and depletion calculations are performed in conjunction with the 44GROUPNDF5 cross section library [3].

In the criticality calculation models, the complete ES2 storage rack arrangement is represented (see Fig. 1). The ES1 racks are assumed to be completely loaded with fresh uranium fuel assemblies, and the ES2 racks are assumed to be completely loaded either with spent uranium or spent MOX fuel assemblies. For the uranium fuel, the maximum initial ${ }^{235} \mathrm{U}$-enrichment of 5.15 w/o and a theoretical $\mathrm{UO}_{2}$ density is assumed. For the MOX fuel, a bounding initial MOX vector and a bounding MOX density is used, taking into account the fuel data of all MOX fuel assemblies used in reactor cycles 19-33. A bounding value of $4{ }^{\circ} \mathrm{C}$ is used for the moderator temperature. To find the minimum required burnup values of the uranium and MOX fuel assemblies to be loaded into the ES2 racks, the burnup of these fuel assemblies is varied in the criticality calculations.

\section{TREATMENT OF UNCERTAINTIES}

\subsection{Criticality Safety Acceptance Criterion}

According to DIN 25471 [2], sufficient subcriticality is proven for a nuclear fuel system defined by a parameter vector $\boldsymbol{x}$ if the calculated neutron multiplication factor $k(\boldsymbol{x})$ fulfills the following inequality:

$$
k(\boldsymbol{x}) \leq 1-\Delta k_{S}-\Delta k_{U}
$$

Here, $\Delta k_{S}$ denotes the administrative safety margin, and $\Delta k_{U}$ is the sum of bias and uncertainty contributions related to the applied calculation systems and the considered fuel configuration:

$$
\Delta k_{U}=\Delta k_{R}+\Delta k_{N}+\Delta k_{B}+\Delta k_{T}+\Delta k_{A}, \quad \text { with }
$$

$\Delta k_{R}: \quad$ Statistical uncertainty or numerical error related to the calculation of $k(\boldsymbol{x})$

$\Delta k_{N}$ : Bias and uncertainty of $k(\boldsymbol{x})$ resulting from errors in the calculation of the nuclide inventory of the irradiated fuel

$\Delta k_{B}$ : Bias and uncertainty of the calculated neutron multiplication factor estimated from the evaluation of a set of suitable criticality safety benchmark experiments

$\Delta k_{T}$ : Uncertainty related to tolerances in the dimensions and material compositions of the nuclear fuel system

$\Delta k_{A}$ : Bias and uncertainty resulting from taking credit for the burnup of the irradiated fuel

According to [1], a margin of $\Delta k_{S}=0.05$ shall be applied to normal operation conditions and design basis accidents. For certain design-exceeding accidents, $\Delta k_{S}$ may be reduced to zero [1].

According to [2], the contributions to $\Delta k_{U}$ shall be expressed as one-sided $95 \% / 95 \%$ tolerance limits provided that they are related to random uncertainties. Since the criticality calculations for 
the Gösgen ESFP are performed with a Monte Carlo program, $k(\boldsymbol{x})+\Delta k_{R}$ is identified with an upper $95 \% / 95 \%$ tolerance limit:

$$
k(\boldsymbol{x})+\Delta k_{R}=\hat{k}(\boldsymbol{x})+\lambda_{95 / 95} \hat{\sigma}(\boldsymbol{x}) .
$$

Here $\hat{k}(\boldsymbol{x})$ is the estimator of the true neutron multiplication factor derived from the statistics of Monte Carlo $k_{\text {eff }}$ values, $\hat{\sigma}(\boldsymbol{x})$ is the square root of the empirical variance of $\hat{k}(\boldsymbol{x})$, and $\lambda_{95 / 95}$ is a sample-size-dependent factor which guarantees that - according to the definition of the upper $95 \% / 95 \%$ tolerance limit - a portion of at least $95 \%$ of the unknown distribution of $k(\boldsymbol{x})$ is located below $\hat{k}(\boldsymbol{x})+\lambda_{95 / 95} \hat{\sigma}(\boldsymbol{x})$ with a confidence of $95 \%$.

Reactivity effects due to tolerances in the dimensions and material compositions of the fuel assemblies and storage racks are covered by choosing bounding values for the corresponding parameters, leading to maximum reactivity. Uncertainties in the calculation of the nuclide inventory of the irradiated fuel are covered by choosing bounding depletion conditions in the burnup calculations and by applying isotopic correction factors to the calculated isotopic concentrations (see Section 3.3). The term $\Delta k_{A}$ takes into account reactivity effects related to non-uniform burnup distributions of the spent fuel assemblies. These reactivity effects are, however, already covered by using bounding axial burnup distributions in the criticality calculation models (see Section 3.4). For the above-mentioned reasons, the terms $\Delta k_{T}, \Delta k_{N}$, and $\Delta k_{A}$ may be neglected in Eq. (2).

In order to take into account also the reactivity increase $\Delta k_{D}$ related to the most reactive design basis accident (drop of a fuel assembly next to an ES2 rack), the acceptance criterion is supplemented by this contribution. Hence, Eq. (1) can be written as follows:

$$
\hat{k}(\boldsymbol{x})+\lambda_{95 / 95} \hat{\sigma}(\boldsymbol{x}) \leq 0.95-\Delta k_{B}-\Delta k_{D} .
$$

The $\Delta k_{D}$ contribution is determined in the criticality analysis of the design basis accidents.

\subsection{Bias and Uncertainty of the Calculated Neutron Multiplication Factor}

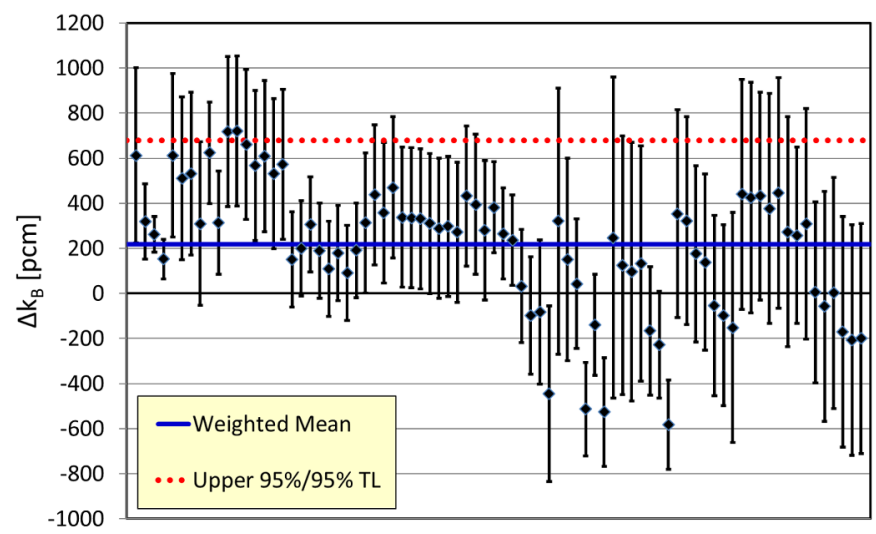

Figure 2: Differences between Experimental and Calculated Neutron Multiplication Factors for 80 Criticality Benchmark Experiments

For the validation of the applied criticality sequence with respect to the considered application case, 80 criticality benchmark experiments from the ICSBEP handbook [5] with low-enriched 
$\mathrm{UO}_{2}$ and $\mathrm{PuO}_{2}$ fuel rod lattices in pure water and in high density configurations with stainless steel and borated stainless steel plates are recalculated. The bias of the criticality calculation procedure is then estimated from the differences $\Delta k_{B}$ between the experimental and calculated neutron multiplication factors. Fig. 2 shows the $\Delta k_{B}$ values obtained for the considered experiments and their standard deviations (error bars) which take into account the experimental and Monte Carlo uncertainties. The solid line represents the weighted mean and the dotted line the upper 95\%/95\% tolerance limit of $\Delta k_{B}$ [4]. This upper $95 \% / 95 \%$ tolerance limit is identified with the bias term $\Delta k_{B}$ in Eq. (4) in accordance with [2].

\subsection{Bias and Uncertainty Related to the Calculation of the Nuclide Inventory}

To cover the reactivity impact of the irradiation history, bounding depletion parameters are used in the burnup calculations [6] which are derived from core design calculations performed for reactor cycles 19-39 at KKG. In particular, we choose upper bound values for the fuel temperature, the moderator temperature, and the critical boron concentration to maximize the plutonium buildup rate via neutron capture in ${ }^{238} \mathrm{U}$. Since this maximizes the plutonium fission rate and, as a result, minimizes the ${ }^{235} \mathrm{U}$ fission rate, the reactivity of the irradiated fuel is maximized.

Nuclides to be taken into account in the criticality calculations are selected on the basis of their reactivity worth, nuclear stability and non-volatility [7]. To cover the accumulation of ${ }^{239} \mathrm{Pu}$ due to ${ }^{239} \mathrm{~Np}$ decay after reactor shutdown, the ${ }^{239} \mathrm{Pu}$ number density is increased by the number density of ${ }^{239} \mathrm{~Np}$.

The validation of the TRITON depletion sequence is based on chemical assay measurements of 90 different spent fuel samples with well-defined irradiation histories from 9 different LWR plants described in [8]: Trino Vercellese (31 samples), Obrigheim (5 samples), Turkey Point Unit 3 (5 samples), H.B. Robinson Unit 2 (6 samples), Calvert Cliffs Unit 1 (9 samples), Takahama Unit 3 (11 samples), Three Mile Island Unit 1 (19 samples), Gösgen / ARIANE Program (3 samples), Neckarwestheim Unit II / REBUS Program (1 sample).

To estimate the error of the burnup calculation procedure, for each experiment and each measured isotope in the spent fuel sample, the deviation of the calculated isotopic concentration $C$ from the experimental isotopic concentration $E$ is expressed in terms of an $E / C$ ratio. Fig. 3 shows the sample mean values and the sample standard deviations (error bars) of the $E / C$ ratios for the considered isotopes. They are the basis for the evaluation of isotopic correction factors (ICFs) to be applied to the calculated isotopic number densities in order to correct for the isotopic bias [11]. To account for statistical uncertainties, the ICFs are identified with upper 95\%/95\% tolerance limits for fissile isotopes and with lower 95\%/95\% tolerance limits for neutron absorbers (see Fig. 3). Since ${ }^{235} \mathrm{U}$ and ${ }^{238} \mathrm{U}$ are initially present in the fuel, the $E / C$ ratios and ICFs refer to the depleted portions for these isotopes (see Fig. 3).

By using bounding depletion parameters in the burnup calculations and ICF-corrected isotopic number densities in the criticality calculations, the uncertainties related to the calculation of the spent fuel nuclide inventory are covered in accordance with [2]. 




Figure 3: E/C ratios of Isotopic Concentrations and Derived ICFs

\subsection{Reactivity Effects Related to Burnup Profiles}

Axial burnup distributions have a considerable influence on the reactivity of spent fuel assemblies. For this reason, the reactivity effect associated with non-uniform axial burnup profiles has to be covered in the criticality safety analysis.

For low fuel assembly burnup, it is bounding to assume a uniform axial burnup distribution because the amount of fissile material is overestimated in the center region of the active zone which determines the reactivity of the fuel assembly. With increasing burnup, however, the reactivity maxima move towards the ends of the active zone where the burnup is low. Axial burnup profiles with maximum asymmetry then lead to the highest reactivity [9]. Since it is not known a priori above which fuel assembly burnup value the assumption of a uniform axial burnup distribution is not bounding anymore, criticality calculations are performed both for uniform burnup profiles and burnup profiles with maximum asymmetry. The more reactive of the two cases is then used for the determination of the minimum required fuel assembly burnup. This procedure ensures a bounding treatment of the reactivity effect of axial burnup profiles for any burnup.

For the generation of bounding axial burnup profiles, the Multivariate Normal Bayesian Model (MNBM) procedure described in [10] is applied to a database of 67,863 burnup profiles from core design calculations, taking into account all uranium and MOX fuel assemblies used in reactor cycles 19-39 at KKG. To obtain profiles with bounding asymmetry, suitable burnup-dependent linear constraints are imposed on the relative top and bottom node burnup values of the profiles [10]. Applying the MNBM procedure then yields axial burnup profiles with bounding asymmetry as smooth functions of average fuel assembly burnup, maintaining the correlations between the relative node burnup values and between the average burnup and the shape of the profile (see Fig. 4). 


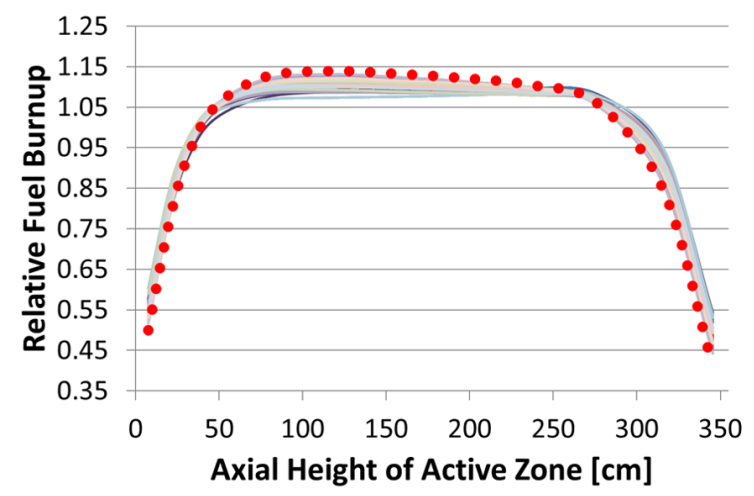

a) Uranium Fuel, $\mathrm{B}=36 \mathrm{GWd} / \mathrm{tHM}$

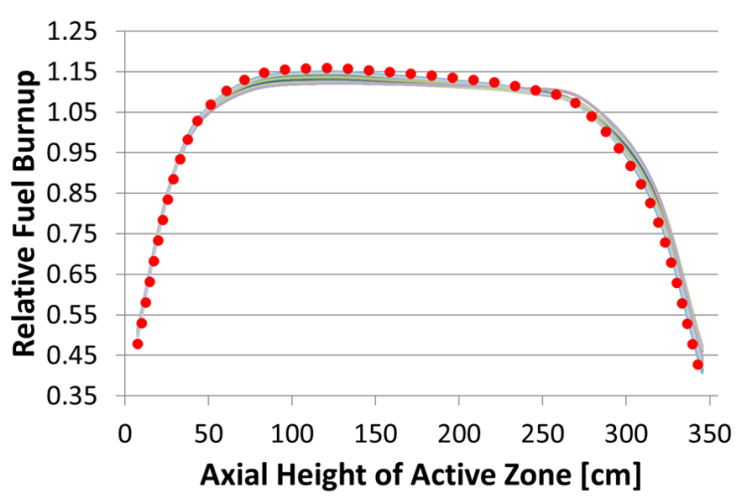

b) MOX Fuel, $\mathrm{B}=38 \mathrm{GWd} / \mathrm{tHM}$

\section{Figure 4: Comparison of Bounding Axial Burnup Profiles (Dotted Lines) to Profiles from the Data Base with Average Burnup Values Close to Those of the Bounding Profiles}

\section{SUMMARY OF RESULTS}

In Fig. 5, the calculated neutron multiplication factors $k_{\text {eff }}$ are presented as functions of the burnup of the fuel assemblies stored in the ES2 racks. Four different cases are considered, corresponding to loadings of the ES2 racks either with uranium or MOX fuel assemblies having either uniform axial burnup distributions or axial burnup distributions with bounding asymmetry. The solid curves in Fig. 5 represent linear least squares fits of the $k_{\text {eff }}$ values to polynomial models, and the dotted curves are the corresponding upper 95\%/95\% tolerance limits [4].
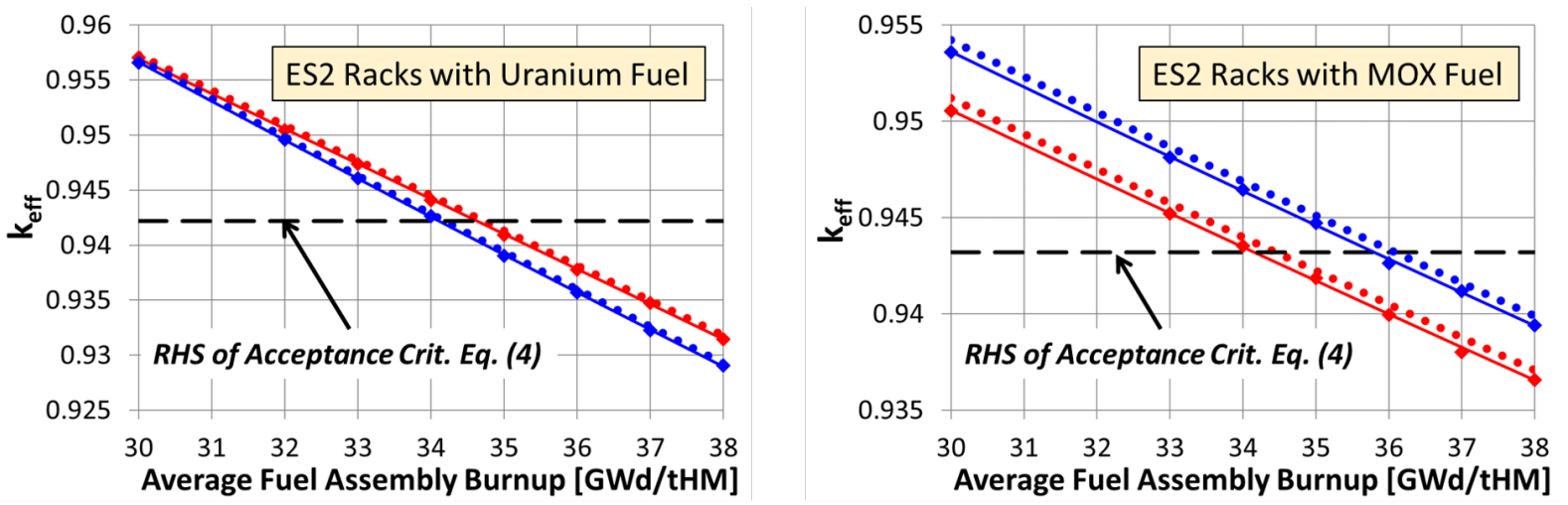

Blue: Uniform Axial Burnup Profile

Red: Axial Burnup Profile with Bounding Asymmetry

_ Linear Least Squares Fit

..... Upper 95\%/95\% Tolerance Limit

Figure 5: $k_{\mathrm{eff}}$ as a Function of the Burnup of the Fuel Assemblies in the ES2 Racks

For uranium fuel, the highest reactivity is obtained for axial burnup profiles with bounding asymmetry, while for MOX fuel the assumption of uniform axial burnup profiles represents the bounding case. According to Eq. (4), the minimum required burnup is defined by the burnup value where the upper 95\%/95\% tolerance limit of $k_{\text {eff }}$ (dotted curves in Fig. 5) is equal to the righthand side of Eq. (4) (dashed lines in Fig. 5). Hence, as follows from the evaluations in Fig. 5, 
the minimum required burnup of the fuel assemblies to be loaded into the ES2 racks amounts to $35 \mathrm{GWd} / \mathrm{tHM}$ for uranium fuel assemblies and $37 \mathrm{GWd} / \mathrm{tHM}$ for MOX fuel assemblies. To cover also the comparatively small reactivity effect related to horizontal burnup profiles [11], a contribution of $1 \mathrm{GWd} / \mathrm{tHM}$ is added to the above minimum required burnup values.

\section{CONCLUSIONS}

The obtained minimum required burnup values of the fuel assemblies to be loaded into the ES2 storage racks of the Gösgen ESFP amount to $36 \mathrm{GWd} / \mathrm{tHM}$ for uranium fuel assemblies and to $38 \mathrm{GWd} / \mathrm{tHM}$ for MOX fuel assemblies. These values are sufficiently low to expect that the vast majority of fuel assemblies to be stored in the ESFP is going to fulfil the loading criterion for the ES2 racks. The MOX fuel assemblies used in reactor cycles 19-33 all have burnup values of more than $50 \mathrm{GWd} / \mathrm{tHM}$. Hence, they may either be stored in the ES1 or the ES2 racks.

In conclusion, using burnup credit makes it possible to increase the number of fuel assemblies per storage area in the ESFP by a factor of 1.3, which leads to considerable cost savings.

\section{REFERENCES}

[1] ENSI-G20 Guideline for Swiss Nuclear Installations: Reactor Core, Fuel Assemblies and Control Rods: Design and Operation, Swiss Federal Nuclear Safety Inspectorate (2015).

[2] DIN 25471 Safety Standard: Criticality Safety Taking into Account the Burnup of Fuel Elements when Handling and Storing Nuclear Fuel Elements in Fuel Pools of Nuclear Power Plants with Light Water Reactors, German Institute for Standardization DIN (2009).

[3] SCALE: A Comprehensive Modeling and Simulation Suite for Nuclear Safety Analysis and Design, Versions 6.0 / 6.1, ORNL/TM-2005/39 (2009 / 2011).

[4] J. C. Neuber, "Burnup Credit Applications to PWR and BWR Fuel Assembly Wet Storage Systems," Proc. Int. Conf. on the Physics of Nuclear Science and Technology, Long Island, New York (1998).

[5] International Handbook of Evaluated Criticality Safety Benchmark Experiments, NEA/NSC/DOC(95)03 (2009).

[6] M. D. DeHart, Sensitivity and Parametric Evaluations of Significant Aspects of Burnup Credit for PWR Spent Fuel Packages, ORNL/TM-12973 (1996).

[7] J. C. Neuber, Criticality Analysis of PWR Spent Fuel Storage Facilities inside Nuclear Power Plants, IAEA-TECDOC-1089 (1999).

[8] G. Radulescu, I. C. Gauld, G. Ilas, SCALE 5.1 Predictions of PWR Spent Nuclear Fuel Isotopic Compositions, ORNL/TM-2010/44 (2010).

[9] J. C. Neuber, "Generation of Bounding Axial Burnup Profiles as a Continuous Function of Average Burnup," Proc. 7th Int. Conf. Nuclear Criticality Safety (ICNC 2003), Tokai, Japan (2003).

[10] A. Hoefer, O. Buss, and M. Schmid, "Applications of Multivariate Normal Bayesian Models in Nuclear Engineering," Nuclear Technology, https://doi.org/10.1080/00295450.2018. 1560784 (2019).

[11] J. C. Wagner, C. E. Sanders, Assessment of Reactivity Margins and Loading Curves for PWR Burnup Credit Cask Designs, NUREG/CR-6800 (ORNL/TM-2002/6) (2003). 